\title{
Histopathological Variations in Gills, Liver and kidney of Nile tilapia-Oreochromis niloticus Exposed to BenzalkoniumBhloride Mixture with Treated Produced Water
}

\author{
${ }^{1 *}$ IKISA, KG; ${ }^{2}$ BABATUNDE, BB; ${ }^{2}$ HART, AI \\ ${ }^{I}$ Institute of Natural Resources, Environment and Sustainable Development (INRES), University of Port Harcourt, Rivers State, Nigeria. \\ ${ }^{2}$ Department of Animal and Environmental Biology, Faculty of Science, University of Port Harcourt \\ *Corresponding Author Email: kariebigrant@gmail.com; other author's email: bolaji.babatunde@uniport.edu.ng
}

\begin{abstract}
ABSTACT: The microscopic examination of tissue in order to study the manifestations of disease is very important. This paper investigated the histopathological variation in some organs of juveniles of Nile tilapia-Oreohromis niloticus exposed to benzalkonium chloride (BAC)-treated produced water (TPW) mixture in a 96hour acute toxicity test. Fish specimens of average body length and weight $7.80 \mathrm{~cm}$ and $25.05 \mathrm{~g}$, respectively were used. At the end of exposure 2 survivor fish in each concentration across triplicates were randomly harvested for the histological examination. Histological preparations of gills, kidney and liver were analysed for histopathological alterations. Results of histological examination revealed various degrees of legions ( gills- cellular necrosis and epithelial rupture $(\mathrm{CN})$, kidney - glomerular expansion (GE) and dilation of Bowman's space (BC) and liver - expanded central vein (CV) and melanomacrophages aggregate (M)) depending on concentrations of the toxicant as against untreated (control) that recorded no abnormality. The results showed that the severity of tissue alterations recorded was a function of toxicity ofbenzalkonium chloride (BAC) mixture with treated produced water (TPW). It is strongly recommended its disposal followed a thorough treatment.
\end{abstract}

\section{DOI: https://dx.doi.org/10.4314/jasem.v23i6.28}

Copyright: Copyright (C) 2019 Ikisa et al. This is an open access article distributed under the Creative Commons Attribution License (CCL), which permits unrestricted use, distribution, and reproduction in any medium, provided the original work is properly cited.

Dates: Received: 10 April 2019; Revised: 27 May 2019; Accepted 25 June 2019

Keywords: Benzalkonium-chloride, treated-produced-water, histopathology, cellular necrosis, O. niloticus

Various degrees of environmental pollutions have been reported over the years as a result of consistent exploration and exploitation of petroleum hydrocarbons in large amounts by multinational oil companies in Nigeria whose activities are mostly concentrated in the Niger Delta since 1958 (Nwilo and Badejo, 2007). Studies have revealed that the Niger Delta has an estimate of 606 oil drilling points (fields) out of which 360 are located offshore and 246 located onshore whereby placing the country as one of the top producers of oil(Piepzyk et al., 2009). The petroleum hydrocarbon exploration has left indelible environmental pollution footprints amid other economic potentials. Oil exploration activities utilise a range of chemicals and as well generate wastes. Some group of these chemicals are the quaternary ammonium compounds such as benzalkonium chloride (BAC), and produced water generated from oil production processes. The vast application of quaternary ammonium compounds (QACs) such as bezalkonium chloride (BACs) as biocide and corrosion inhibitor in the oil and gas exploration and exploitation processes, as well as in agriculture and other industrial practices in the Niger Delta has resulted either directly or indirectly in the release of these compounds and produced water into the aquatic environment which has a serious toxic potential on aquatic biota (Zhang et al., 2015). Consequently, a good number of QACs are known for their genotoxic potentials in the cells of mammals and plants as well as crustaceans (Lavorgna et al., 2016). Also, as a result of their eco-toxicological characteristics and relative abundance in wastewaters and aquatic habitats, quaternary ammonium compounds are of great environmental concern. Studies showed that histopathology is one dependable scientific approach used in drawing conclusion in toxicological evaluation of substances in biological systems (Ali and Fishar, 2005).Histopathological variations serve as indicators in the determination of the impact of contaminants on aquatic fauna. These bio-indicators formed synergy with related stress markers due to metabolic activation activities of pollutants prior to cellular alterations of impacted biota (Ali and Fishar, 2005).

It is reported that when fish are subjected to contaminants they are bound to suffer various degrees of histopathological changes within tissues and as directly put by Abbas and Ali, (2007). Exposure of fish to various toxicants can trigger histological lesions in the muscles. The liver as a sensitive organ of metabolism has the potential of taking up xenobiotics 
from the aquatic environment. Studies revealed that histological bio-indicators utilised in biological monitoring paves way for target organs such as gills, kidney and liver which are metabolically active sites for gaseous exchange, removal of toxic substances as well as bio-concentration and biotransformation of xenobiotics in fish. Additionally, the changes detected in these tissues are usually easier to recognize than functional, and serve as caution symbols of harm to animal health (Hinton and Lauren, 1990). Gills are the primary contact points of contaminants as a result of their direct contact with the surrounding environment. Consequently, the liver is responsible excretion of toxic substances as well as regulation of biotransformation process (Van der Oost et al., 2003).The kidney is one of the primary organs susceptible to contaminants in aquatic environment (Thophon, 2003).Therefore, the aim of this research was to investigate the histological effect of benzalkonium chloride mixture (with treated produced water) on gill, liver and kidney of Nile tilapiaOreochromis niloticus.

\section{MATERIALS AND METHODS}

Sampling: A total of one hundred juveniles of freshwater tilapia-Oreochromis niloticus were obtained from the African Regional Aquaculture Centre (ARAC), Aluu, Port Harcourt, Rivers State, Nigeria in the early hours of the day and transported to the experimental lab (aquarium) at the Department of Animal and Environmental Biology, University of Port Harcourt, Rivers State in four 50Ltr black plastic containers with an open end containing sufficient habitat water to sustain fish life. The fish of average weight $(25.05 \mathrm{~g})$ were acclimatized for 14 days in two (2) large glass holding tanks measuring $100 \times 100 \times 50$ $\mathrm{cm}$ with well aerated de-chlorinated water. During the acclimatization period, the fish were fed twice daily (morning and evening) at $3 \%$ total body weight with commercial feeds (Coppens) obtained from source. Mortality rate was below 3\% during acclimatization as the water was renewed every 24 hours to eliminate hoarded faecal material and unconsumed feed. Feeding was discontinued 24 hours prior to 96hours (acute) exposure. Procedure followed recommendations of OECD (2001 a).

Experimental Design: 5 juvenile fish of both sexes were randomly collected and stocked in each of the 15 glass containers (triplicate) measuring $40 \times 25 \times 25 \mathrm{~cm}$ with $0.25 \mathrm{~mm}$ diameter (containing $5 \mathrm{~L}$ of test solution and de-chlorinated water as control) with opening covered by means of fastened wire gauge were used for the experiment. The fish were subjected to variable concentrations of benzalkonium chloride mixture with treated produced water (0.00 (control), 20.20, 50.50,
101.00 and $202.00 \mathrm{ppm})$. The experiment lasted for $96 \mathrm{~h}$.

Histological examinations: From each concentration of the three replicates, 2 fish were collected after 96 hours and sacrificed by cutting the head using sharp dissecting carbon steel, weighed and overall length recorded. Samples of vital organs such as gills, liver and kidney were harvested from each fish including the control for histological analysis.

Slide preparation: Fish samples were dissected using surgical blade. The gills were carefully harvested from each fish. The liver from each fish was harvested (dissected) without damaging the gall bladder. The kidney was carefully harvested from the posterior end. The histopathological method employed were those described by Golder Associates (2007).

Tissues were placed in a tissue slide and fixed instantly in $10 \%$ neutral formalin in Nalgene jug for 24 hours as described by Alen et al., (1983). To prevent fouling, the samples were washed under running tap for two hours and then dehydrated in $95 \%$ ethanol. They were then transferred to xylene for $5 \mathrm{~min}$ until the emergence of transparent coloration and then later taken to the oven. Three slides were prepared for each concentration including control for quality control and quality assurance purposes to get a standard deviation of effect around mean effect for each treatment.

The solution samples were penetrated and implanted in paraffin wax. After cooling of the implanted samples, sections were made and dried using microtome. Then staining of sections were done using haemotoxylin and eosin (H\&E). Microscopic examination was preceded by mounting of slides with cover slips. Binocular microscope (LEICA DM750 (model; LEICA ICC50HD) was used for viewing at $\mathrm{x} 100$ magnification and as well used for the photomicrography. Results obtained were used for histological interpretation and reporting.

\section{RESULTS AND DISCUSSIONS}

Histopathology of the Gills of Tilapia- Oreochromis niloticus: Structurally, there are four gills architectures on either sides of the buccal opening (cavity). Each gill arch comprises of enormous gill filaments and two rows of secondary lamellae are vertically arranged to the gill filaments. The secondary lamellae comprises of contractile cells that demarcated the tube (capillary) channels. Contained in the tube (capillary) lumen were between one and two red blood cells (erythrocytes). It was observed that the base of lamellae comprised of filaments mucous cell impregnated epithelium that were deficit of cytoplasm (Peebuaa et al., 
2006).Histological examination of the gills of Oreochromis niloticus revealed unaltered arrangement in control (untreated) fish (plates $1 \mathrm{~A}$ ) as against various degrees of histological alterations exhibited by the exposed (treated) group (plates $1 \mathrm{~B}, \mathrm{C}, \mathrm{D}, \mathrm{E})$. The various histological alterations observed were as follows: Blood congestion (BC), hyperplasia (H) and fusion of some lamellae (FL), vasodilatation (V) with blood congestion $(\mathrm{BC})$, cellular hypertrophy $(\mathrm{CH})$, telangiectasis at the tips of secondary lamellae $(\mathrm{T})$, epithelial lifting (EL) and interstialedema (IE), cellular necrosis and epithelial rupture $(\mathrm{CN})$, hypertrophy of the lamellar epithelium $(\mathrm{H})$ and partial fusion of somelamellae (PF).The gills are vital organs responsible for regulating the internal and external interaction, maintenance of respiratory processes, acid-alkali balance and as well excretion of nitrogenous wastes. It was suspected that the histological alterations of the gills were due to uptake of heavy metals and total petroleum hydrocarbon contained in the toxicant found in the test water. The gills are considered as susceptible architecture of the teleostean fish due to their direct contact with the external aquatic environment and as such prone to harmful attack by toxicants present in water in either their soluble or insoluble state. This study has revealed that benzalkonium chloride (BAC) mixture with treated produced water has acute lethal impacts on tilapia-Oreochromis niloticus.

According to Kantham and Richards (1995), cellular hyperplasia may cause an increase in the epithelial wall thereby impeding into the blood flow. Lamellar fusion could be a resultant effect of cell multiplication and rise in girth of gill filament epithelium (Figueiredo-Fernandes, 2007).

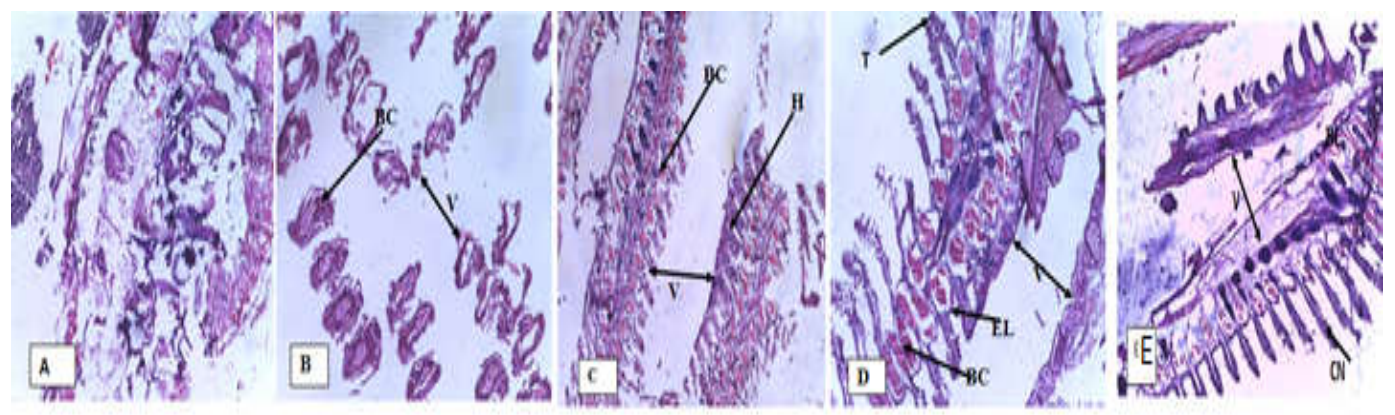

Plate 1: Photomicrograph of the gills of Oreochromis niloticus after 96 hours of exposure to toxicant (benzalkonium chloride mixture with treated produced water).x100

(A) -Control (B) - 202.00ppm: Blood congestion (BC), Hyperplasia (H) and fusion of some lamellae (FL), Vasodilatation (V) with blood congestion $(B C)(C)-101.00 p p m$ : Blood congestion $(B C)$, Cellular hypertrophy $(C H)$, Hyperplasia $(H)$ and partial fusion of some lamellae $(P F)(D)$ - 50.50ppm: Blood congestion (BC), Vasodilatation (V) with blood congestion (BC), slight formation of telangiectasis at the tips of secondary lamellae (T), epithelial lifting (EL) and interstialedema (IE) (E) - 20.20ppm: Vasodilatation (V) with blood congestion (BC), telangiectasis at the tips of secondary lamellae $(T)$, cellular necrosis and epithelial rupture $(C N)$.

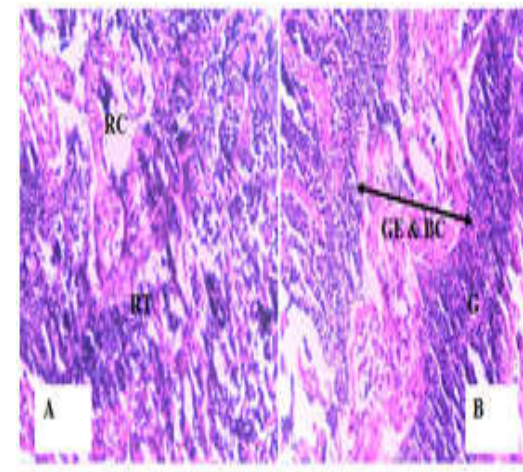

Plate 2: Photomicrograph of the kidney of Oreochronis
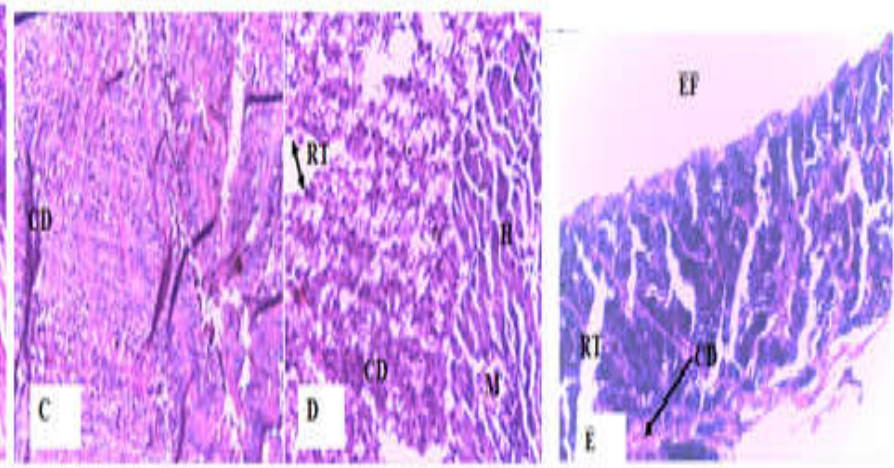

$$
\text { treated produced water).x100 }
$$

(A) -Control (B) - 202.00ppm: Glomerular expansion (GE) and dilation of Bowman's space (BC), deterioration of glomerulus (G), increase in diameter of renal tubule $(R T)(C)-101.00 p p m:$ Acute cellular degeneration and occlusion of the tubular lumen (CD) (D) -50.50ppm: Increase in diameter of renal tubule $(R T)$, cellular degeneration $(C D)$, melanomacrophages aggregate $(M)$ with hemorrhage $(H)$ (E) 20.20ppm: Increase in diameter of renal tubule (RT), edematous fluid (ED) cellular degeneration (CD). 


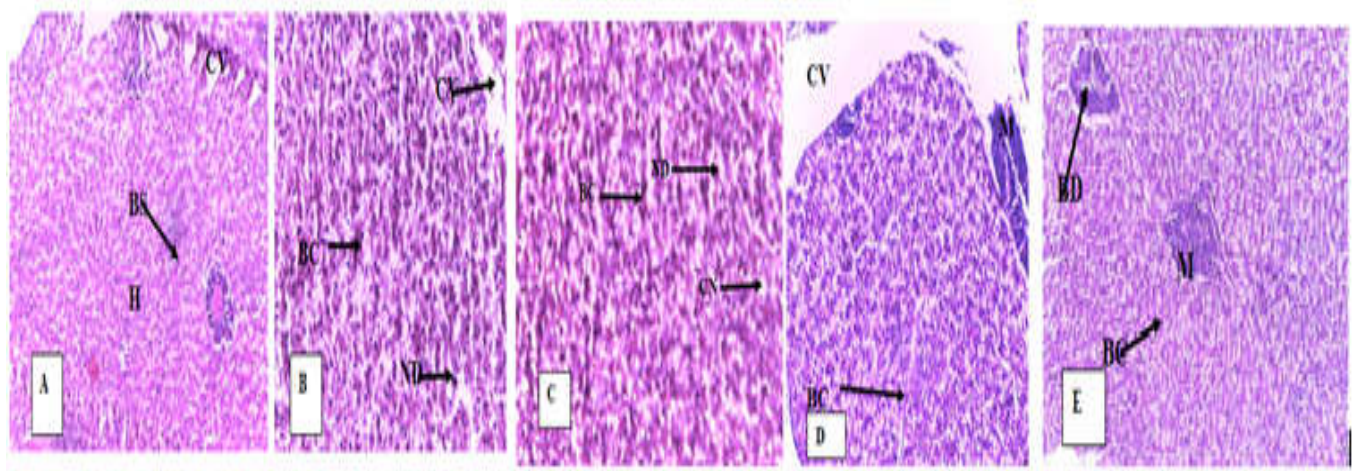

Plate3: Photomicrograph of the Liver of Oreochromis niloticus after 96 hours of exposure to toxicant (benzalkonium chloride mixture with treated produced water).x100

(A) -Control (B) - 202.00ppm: Tissue showing expanded central vein (CV), blood congestion (BC) and nuclear degeneration (ND) (C) 101.00ppm: Tissue showing cellular necrosis (CN), blood congestion (BC) and nuclear degeneration (ND) (D) -50.50ppm: Tissue showing expanded central vein $(C V)$, blood congestion $(B C)$ and melanomacrophages aggregate $(M)(E)-20.20$ ppm: Melanomacrophages aggregate $(M)$ close to a bile duct (BD), and blood congestion (BC)

Toxin in toxic substances has the potential to interfere in the glycoprotein building process in the mucus covering of cells thereby disrupting the negative ions (charge) of the epithelium with a resultant impact of cellular synthesis (fusion) and hyperplasia of lamellae. Pane et al., (2004) in their work justified that epithelial lifting of the lamellar could have been caused by the occurrence of severe edema. Other related studies discovered that interstitial edema is histological alteration that occurs regularly in gill epithelium of fish exposed to heavy metals. With respect to the reports of Garcia-Santos et al., (2006) vasodilatation has the potential of inducing alteration in pillar cell normal architecture with relative loss of their support responsibility and uncertainly was the reason for the appearance of lamellar aneurysms. Hence, affected (damaged) pillar cells can trigger a rise in blood flow within the lamellae thereby resulting in expansion (dilation) of the subsidiary canal, blood congestion and aneurysm (Rosety-Rodriguez et al., 2002). Telangiectasis histological alteration was borne out of cell cleavage from pillar cells and capillaries which could be due to heavy metals pollution with a resultant effect of bio-concentration of erythrocytes in the distal area of the secondary lamellae. It was also observed that defence mechanisms gave rise to epithelial lifting, hyperplasia and hypertrophy of the epithelial cells, with the exception of partial fusion of some secondary lamellae thereby increasing the distance between the external surrounding and the blood and as well serve as a demarcation to the entrance of contaminants. This action of increase in distance between the internal and external surrounding can lead to impaired oxygen assimilation (Fernandes and Mazon, 2003).According to Alazemiet al., (1996) these identified histological alterations of the gills of Oreochromis niloticus are likely resulted in hypoxia, respiratory malfunction problems with ionic and acid-alkali equilibrium. Also, the associated iono- and osmoregulatory malfunction leads to rapid cell necrosis and eventual death of fish.

Histopathology of the Kidney of Tilapia Oreochromis niloticus: The kidney examined was made up of several renal corpuscles with well pronounced glomeruli and a network of canals (tubules). The columnar epithelial cells which are made up of basal nuclei and brush border found at the tips of the cell provides coverage for the proximal segment. The distal segment was wrapped in huge, relatively transparent columnar epithelial cells which comprises of central nuclei with the absence of brush lining (Peebuaa et al., 2006).Histological examination of the kidney of Oreochromis niloticus revealed a normal structural arrangement in control (untreated) fish (plate 2: A) as against various degrees of histological alterations exhibited by the exposed (treated) group (plates 2: B, C, D, E). The different histological changes observed were as follows: glomerular expansion (GE) and dilation of Bowman's space $(B C)$, deterioration of glomerulus $(\mathrm{G})$, increase in diameter of renal tubule (RT), acute cellular degeneration and occlusion of the tubular lumen (CD), melanomacrophages aggregate $(\mathrm{M})$ with hemorrhage $(\mathrm{H})$, edematous fluid (ED) and shrinkage of renal corpuscle (RC).According to Thophon et al., (2003), one of the first organs to be negatively impacted by contaminants is the teleostean kidney. The hydropic swelling morphological variation of the urinary tubules was due to cellular hypertrophy and as well the occurrence of tiny particles in the cytoplasm which is net-like in form. These tiny particles could be synthesized within the cells or via assimilation of 
plasma proteins lost in the urine, signifying harm within the corpuscle (Takashima and Hibiya, 1995). Disruption of existing processes at the molecular and subcellular levels of biological organization by xenobiotics can damage cell, resulting in a degenerative and neoplastic diseases in target organs (Pacheco and Santos, 2002).

As reported by Takashima and Hibiya, 1995) cellular degenerative processes can result in tissue necrosis in very severe scenarios. It was revealed from the study that bio-concentration of BAC mixture resulted in the collapse of glomeruli and blood hemorrhage and can lead to rise in the level of edematous fluid within interstitial substance.

Histopathology of the Liver of Tilapia - Oreochromis niloticus: The liver consists of hepatocytes with two cells thick unique branching laminae arrangement that is separated by sinusoid. Hepatocytes are characterized by polygonal cells with a centralized nucleus and a darkly stained nucleolus (Figueiredo-Fernandes et al., 2007). Histological study showed a normal tissue internal arrangement pattern of the liver in the control (untreated) fish (Plate 3: A). Result showed that no pathological alterations were observed in untreated fish as against various degrees of histological alterations exhibited by the exposed (treated) group (plate 3: B, C, D, E).Observed noticeable alterations included hepatocytes hypertrophy $(\mathrm{HH})$ and melanomacrophages aggregate (M), nuclear hypertrophy(NH) and nuclear degeneration (ND), melanomacrophages aggregate $(\mathrm{M})$ close to a bile duct (BD), cellular degeneration (CD), cellular necrosis $(\mathrm{CN})$ and blood congestion (BC) and tissue showing expanded central vein $(\mathrm{CV})$. This study has shown that increase in concentration of BAC mixture with treated produced water resulted in cytoplasmic vacuolation, cellular degeneration, damage of nuclei, bile stagnation as well as clogging in the blood sinusoids. Heavy metals have the potentials of causing an increase or decrease of enzymatic processes and as such result in histological alterations. However, this process is dependent on the type of metal, concentration, fish species and exposure duration. Studies showed that hepatocytes could be the main target sites of poisonous materials thereby providing first-rate biological marker of aquatic contamination. One sure way of assessing the impacts of xenobiotic compounds emanating from field and laboratory studies is to constantly check the level of histological variations in the liver of exposed fish (FigueiredoFernandes et al., 2007).Hypertrophy is a function of increase in the size of cell. Thus, exposure to toxic materials that have the ability of propagating cells within the endoplasmic reticulum membranes can be considered as hypertrophy. According to Peebuaa et al., (2006) hydropic inflammation is a function of exposure of Oreochromis niloticus to polluted sediment. With regards to findings of FigueiredoFernandes et al., (2007) enlargement of hepatocytes could be as a result of increase in the amount of lipids. Consequently, Braunbeck et al., (1990) stated that changes in the form of nucleus could be due to high metabolic processes emanating from pathological source. The usual metabolic processes of the liver is functionally related to the presence of glycogen and fats in the vacuoles of the hepatocyte cells. Hence, the presence of vacuoles in the hepatocyte cells signals a disparity between the speed of production of substances in the parenchymal cells and the speed of their discharge into the systemic flow. The propagation of vacuoles in the hepatocytes is an indication of cellular destructive process that infers metabolic damage, which could be due to exposure to polluted water. The presence of bile stagnation and dispersal of melanomacrophages in the parenchymal tissues of the liver is an indicator of damage structurally and metabolically which is a function of exposure to toxicant. This build-up of bile signals possible harm to the hepatic metabolism. A rise in the density of melanomacrophage aggregates is usually correlated to vital hepatic alterations (Pacheco and Santos, 2002), such as degenerative and necrotic processes. These histological alterations in the liver could result in anoxia due to deterioration of the gills which to a large extent can cause cell damage and devastation]. These harmful activities affect exchange of oxygen and tissue respiration resulting in organ and tissue hypoxia, disintegration and necrosis (Taiwo et al., 2005). Furthermore, the cellular degeneration and necrosis could be as a result of impacts of accumulation of metals in hepatic tissues.

Conclusion: Results obtained from this present study showed that the degree of damage recorded in the tissues of the organs of the juveniles of Nile tilapiaOreohromis niloticus was induced by benzalkonium chloride (BAC)-treated produced water (TPW) mixture in a 96hour acute toxicity test. This study also revealed that results of histological biomarkers remain viable and reliable way of detecting presence of pollutants in the aquatic environment.

\section{REFERENCES}

Abbas, H; Ali, F (2007).

Studytheeffectofhexavalentchromiumonsomebio

chemical, cytotoxicological and histopathological aspects of the Oreochromis spp. Fish. Pak. J. Biol. Sci., 10: 3973-3982.

Alan, JAS; Geraci, JR; Hudson, PV (1983). Histopathological and physiological response of 
rainbow trout, Salmogairdnerito sub-lethal levels of lead. Water research 17:115-118.

Alazemi B M; Lewis JW; Andrews, E B (1996). Gill damage in the freshwater fish, Gnathonemus ptersii (Family: Mormyridae) exposed to selected pollutants: an ultra-structural study. Environ. Technol.17, 225-238

Ali, M; Fishar,M (2005). Accumulation of trace metals in some benthic invertebrate and fish species relevant to their concentration in water and sediment of Lake Qarun, Egypt. Egypt. J. Aquat. Res., 31: 289-301

Braunbeck T; Storch V; Bresch H (1990). Speciesspecific reaction of liver ultrastructure in zebra fish, Brachydaniorerio and trout, Salmogairdneri after prolonged exposure to 4-chloroaniline. Arch. Environ. Contam.Toxicol. 19, 405-418

Fernandes M N; Mazon A F (2003). Environmental pollution and fish gill morphology. In: Val, A L; Kapoor B G(Eds.), pp. 203-231. Fish adaptations. Enfield, Science Publishers

Figueiredo-Fernandes A; Ferreira-Cardoso J V; Garcia-Santos S; Monteiro SM; Carrola J; Matos P; Fontaínhas Fernandes, A (2007). Histopathological changes in liver and gillepithelium of Niletilapia, Oreochromis niloticus exposed to waterborne copper. Pesq. Vet. Bras., 27(3), 103-109

Garcia-Santos S; Fontaínhas-Fernandes A; Wilson JM; (2006). Cadmium tolerance in the Nile tilapia, Oreochromis niloticus following acute exposure: Assessment of some ionoregulatory parameters. Environ. Toxic. 21(6), 33-46

Golder Associates (2007). Golder technical procedures. Fish health assessment-methods. Ontario, 1997. 28p.

Hinton, DE; Lauren, DJ (1990). Liver structural alterations accompanying chronic toxicity in fishes: potential biomarkers of exposure. In: Biomarkers of Environmental Contamination (Eds.), pp. 17-52. J.F. McCarthy and L.R. Shugart. Lewis Publishers.

Kantham KP; Richards RH (1995). Effect of buffers on the gill structure of common carp, Cyprinuscarpi oand rainbow trout, Oncorhynchus mykiss. Journal of fish diseases, 18, 411-423.
Lavorgna M; Russo C; D’Abrosca B; Parrella A; Isidori M (2016). Toxicity and genotoxicity of the quaternary ammonium compound benzalkonium chloride, BAC usingDaphnia magna and Ceriodaphniadubia as model systems. Environ. Poll. 210:34-39

Nwilo, PC; Badejo, OT (2007). Impacts and Management of Oil Spill Pollution along the Nigerian coasts. International Federation of Surveyors.

Organisation for Economic Co-operation and Development (OECD) (2001 a). OECD Guidelines for the testing of chemicals-Proposal for anew guideline 21 8: Sediment-water chironomid toxicity test using spiked sediment, (http://www.oecd.org/oecd/pages/documentredir ection?paramID $=24311$ \&language $=\mathrm{EN}$ col=OECDDCoreLive).

Pacheco M; Santos M A (2002). Biotransformation, genotoxic and histopathological effects of environmental contaminants in European eel, AnguillaanguillaL. Ecotoxicol. Environ. Safety, 53, 331-347.

Pane EF; Haque A; Wood CM (2004). Mechanistic analysis of acute, Niinduced respiratory toxicity in the rainbow trout, Oncorhynchusmykiss: an exclusively branchial phenomenon. Aquatic Toxicology, 69, 11-24

Peebuaa, P; Kruatrachuea, M; Pokethitiyooka, P; Kosiyachindaa, P (2006). Histological Effects of Contaminated Sediments in Mae Klong River Tributaries, Thailand, on Nile tilapia, Oreochromis niloticus. Sci. Asia, 32, 143-150

Piepzyk, B; Kortluke, N; Rojas Hilje, P (2009). The impacts of fossil fuels: Greenhouse gas emissions, environmental consequences and socio-economic effects. Energy Research Architecture. Final Draft. 9-45.

Rosety-Rodriguez M; Ordoez F J; Rosety M.; Rosety J M.; Ribelles A; Carrasco C (2002). Morphohistochemical changes in the gills of turbot, Scophthalmus maximus L., induced by sodium dodecyl sulfate. Ecotoxicol. Environ. Safety, 51, 223-228

Taiwo VO; Olukunle, OA.;Ozor I C; Oyejobi, A T (2005). Consumption of Aqueous Extract of Raw, Aloe Vera Leaves: Histopathological and 
Biochemical Studies in Rat and Tilapia. Afr. J. Biomed. Res. 8, 169-178

Takashima F; Hibiya T (1995). An atlas offish histology. Normal and pathogical features. 2 nd ed. Tokyo, Kodansha Ltd

Thophon S; Kruatrachue M; Upathan E S ; Pokethitiyook P; Sahaphong S; Jarikhuan S (2003). Histopathological alterations of white seabass, Latescal cariferin acute and subchronic cadmium exposure. Environ. Poll.121, 307-320
Van der Oost R; Beyer J; Vermeulen NPE (2003). Fish bioaccumulation and biomarkers in environmental risk assessment: $A$ review. Environ. Toxicol. Pharmacol. 13, 57-149

Zhang C; Cui F; Zeng G; Jiang M; Yang Z; Yu Z; Zhu M; Cui F; Shen, L (2015). Quaternary ammonium compounds, QACs: a review on occurrence, fate and toxicity in the environment. Sci. Total Environ.518:352-362 